\title{
Photosensitization of PVC dehydrochlorination by hydroquinone for improved optical and electrical properties
}

\author{
Sinan Balci, Ozgur Birer, Sefik Suzer* \\ Department of Chemistry, Bilkent University, 06533 Ankara, Turkey
}

Received 28 February 2004; received in revised form 28 July 2004; accepted 5 August 2004

Available online 3 September 2004

\begin{abstract}
Hydroquinone (HQ) is incorporated into the PVC films containing methyl violet or polyaniline (emeraldine base) for sensitizing the UV induced optical or electrical changes, respectively. It is observed that introduction of a small amount (less than 10\% by weight) of HQ not only brings the dehydrochlorination onset down to $310 \mathrm{~nm}$ but also sensitizes the process by more than one order of magnitude as well as leading to strong polyene formation. UV-Vis-NIR spectroscopy is used to characterize the changes and investigate the mechanism. Accordingly, it is postulated that this HQ assisted photo-dehydrochlorination involves predominantly the formation of an excited triplet via an efficient intersystem crossing in HQ followed by abstraction of hydrogen from the poly(vinyl chloride) to initiate a zipping reaction in the PVC matrix.
\end{abstract}

(C) 2004 Elsevier Ltd. All rights reserved.

Keywords: PVC; Dehydrochlorination; Sensitization

\section{Introduction}

Poly(vinyl chloride) is a multi purpose and common insulating polymer but degrades easily via dehydrochlorination (loss of $\mathrm{HCl}$ ) when exposed to heat, energetic particles or photons [1]. Dehydrochlorination, under certain conditions, may cause alternating single and double carbon bonds, polyenes. Extensive polyene formation leads to yellowing of the PVC matrix together with loss of mechanical properties [2-4]. Numerous studies have been carried out to prevent dehydrochlorination by using stabilizers [5-7]. However, as an alternative, PVC can be thought as a Bronsted acid source with controllable emission. Photodegradation and photochemical modifications of PVC and the resulting polyenes have been extensively investigated [8-10]. Decker claimed that total dehydrochlorination of PVC could be achieved by first photochlorination in the presence of $\mathrm{Cl}_{2}$ and then irradiation with a short $\mathrm{Ar}^{+}$laser at $488 \mathrm{~nm}$ leading to a purely carbon

\footnotetext{
* Corresponding author. Tel.: +90-312-266-4946; fax: +90-312-2664579.

E-mail address: suzer@fen.bilkent.edu.tr (S. Suzer).
}

polymer which was shown to exhibit some electrical conductivity [8]. Ueno reported on development of a high dose plastic dosimeter using dehydrochlorination of PVC under irradiation, which indicated $\mathrm{pH}$ change in the color of a dye contained in the PVC [11]. A similar study was also reported by Sidney et al. for producing a radiochromic dosimeter film by incorporating acid-sensitive leuco dyes in chlorine-containing polymer matrix [12]. In one of our recent studies, we demonstrated that the UV-induced dehydrochlorination could also be used for lithographic purposes, where the color change of the methyl violet (MV) upon capture of the $\mathrm{HCl}$ released was utilized for the purpose [13].

Over the last two decades, PVC has also been used for various applications in the very active field of conducting and/or electroactive polymers, mostly, as the blending medium, for improving chemical and mechanical properties of the conducting polymers [14]. In one study, Ogun reported on preparing laminated polypyrrole/PVC films where photo-dehydrochlorination and doping with $\mathrm{I}_{2}$ or $\mathrm{FeCl}_{3}$ was employed [15]. Wan et al. were able to prepare transparent and conducting PANI/PVC coatings [16]. Ouyand and Chan prepared polypyrrole, PPy/PVC, and 
Laska PANI/PVC conducting films [17,18]. In another recent study, it was reported that exposure to X-rays of the PANI in composite Langmuir-Blodgett films affected the electronic properties in a similar way to acid doping [19]. Sertova et al. utilised the $\mathrm{PVC}$ as a photodonor of $\mathrm{HCl}$ for protonation of PANI [20]. We have also reported similar studies in which dehydrochlorination by the action of UV, $\gamma$-rays or e-beams was utilised to induce doping of polyaniline or 2-chloro-polyaniline incorporated into the PVC matrix in their non-conducting forms [21-23]. In those studies, various spectroscopic techniques were employed to elucidate the changes in the PVC/PANI or the PVC/2-ClPANI composite films upon exposure to these energetic particles. Polyaniline was chosen due to its environmental stability and ease of production [24]. However, the problems with polyaniline, such as lack of processibility and poor mechanical strength of the acidic form compared to highly soluble basic form, still remain unsolved.

Our strategy of blending the basic form of PANI with PVC and later on doping via photo-dehydrochlorination might offer a clean (solvent-free) solution, since both PVC and the basic form of polyaniline (emeraldine base), PANI(EB), are soluble in common organic solvents. Although the conductivity of basic PANI/PVC blends increased from $10^{-6}$ to $10^{-2} \mathrm{~S} \mathrm{~cm}^{-1}$ upon irradiation with $254 \mathrm{~nm}$ source, the maximum conductivity which could be obtained was obviously beyond ideal.

Another attractive point about our strategy is the formation of polyenes within the PVC matrix. Since the total dehydrochlorination (which is almost impossible to achieve) of PVC would lead to polyacetylene (another conducting polymer), partial dehydrochlorination might produce long-enough polyenic segments, which, together with PANI, could produce blends with higher electrical conductivity presently achievable with our methods $\left(10^{-2} \mathrm{~S} / \mathrm{cm}\right)$. PVC, itself, is transparent to normal UV irradiation and only hard $\mathrm{UV}(<250 \mathrm{~nm})$ causes extensive dehydrochlorination. It is also a common knowledge that certain impurities enhance/ trigger photo-dehydrochlorination and shift the wavelength range [1]. We have undertaken the present study for sensitization of the dehydrochlorination using an aromatic compound, hydroquinone (HQ), into the matrix, and have shifted the energy of irradiation to the absorption maximum of it $(\sim 310 \mathrm{~nm})$.

\section{Experimental}

Polyaniline (emeraldine base) and polyvinyl chloride (inherent viscosity: 0.92) were purchased from Aldrich and used as received. MV, was obtained from Fluka. THF was from Carlo Erba, and was freshly distilled over $\mathrm{KOH}$ prior to use. PVC was dissolved in THF to obtain $0.02 \mathrm{~g} / \mathrm{ml}$ solution. This stock solution was used to prepare the 10:1 (w/w) PVC/MV and 1:1 (w/w) PVC/PANI solutions. Blends involving $0.1-20 \% \mathrm{HQ}$ by weight with respect to PVC were also prepared using these solutions. The solutions were cast onto quartz substrates and the solvent was evaporated under saturated THF atmosphere to maintain uniform film formation. The films obtained were about $25 \mu \mathrm{m}$ thick on the average and heated under IR lamp for $5 \mathrm{~min}$ before each experiment to get rid of the solvent residue. Irradiation studies were carried out using a $\mathrm{Hg}$ lamp with a fluorescent coating (Cole Palmer) which provides an output at $312 \mathrm{~nm}$ $\left(8 \mathrm{~mW} / \mathrm{cm}^{2}\right)$ and a low pressure $254 \mathrm{~nm} \mathrm{Hg}$ source (UVP, Model R-52G) at $7 \mathrm{~mW} / \mathrm{cm}^{2}$. Irradiation was carried out from a distance of $5 \mathrm{~cm}$ in $15 \mathrm{~min}$ intervals for a total period of $2 \mathrm{~h}$. UV-Vis NIR spectra were recorded every $15 \mathrm{~min}$ using a Varian Cary 5E spectrophotometer with $300 \mathrm{~nm} / \mathrm{min}$ scanning speed and $2.0 \mathrm{~nm}$ spectral bandwidth. A Zeiss UMSP 80 microscope spectrometer equipped with a $75 \mathrm{~W}$ Xe source was used for the determination of the spectroscopic onset of the dehydrochlorination. Electrical conductivity of the films was measured using a four-point probe.

\section{Results and discussions}

\subsection{Optical modification}

Fig. 1(a) shows a set of UV-Vis spectra of the PVC films containing MV (which is used as the indicator of $\mathrm{HCl}$ evolution), exposed to $312 \mathrm{~nm}$ radiation source. MV has absorption peaks around 580 and $310 \mathrm{~nm}$ which is also capable of absorption of $312 \mathrm{~nm}$ radiation to lead to degradation. However, no appreciable changes can be observed after $2 \mathrm{~h}$ of exposure. In addition, the region between 300 and $450 \mathrm{~nm}$ does not contain any sign of polyenic sequences as opposed to exposure to the harder $254 \mathrm{~nm}$ UV radiation which results in moderate polyene

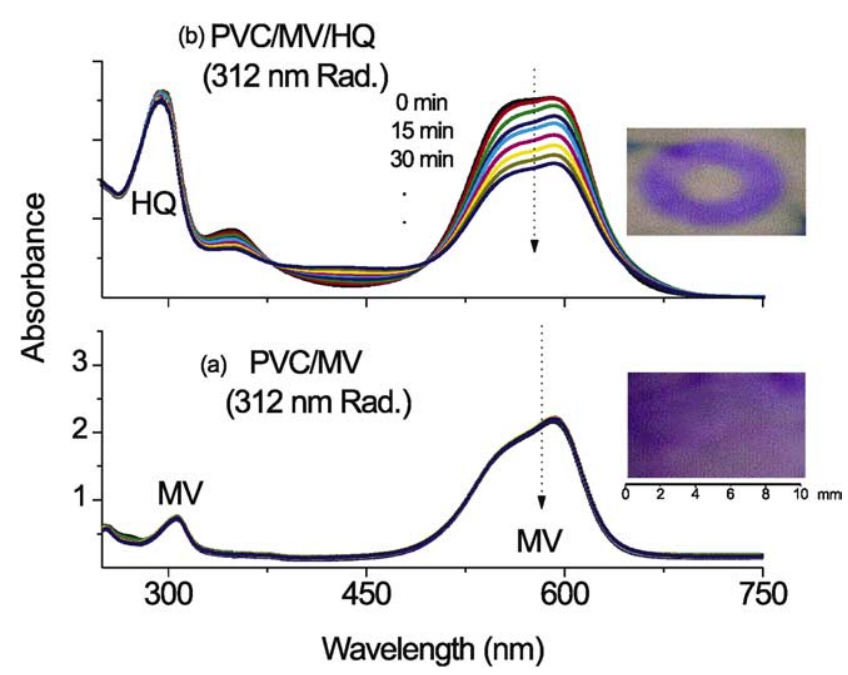

Fig. 1. A set of UV-Vis-NIR spectra of the films. (a) PVC containing (10:1) methyl violet (exposed to $312 \mathrm{~nm}$ radiation), (b) PVC containing methyl violet and HQ (10:1:1) (exposed to $312 \mathrm{~nm}$ radiation). The figure also contains the photographs of the films after $2 \mathrm{~h}$ exposure to the $312 \mathrm{~nm}$ radiation. 
formation. Hence, no measurable photo-dehydrochlorination can be detected with $312 \mathrm{~nm}$, which is also evidenced by the picture of the film after $2 \mathrm{~h}$ exposure given as an inset. Fig. 1(b) shows the same set of spectra in the film containing also HQ irradiated at $312 \mathrm{~nm}$, which clearly leads to extensive dehydrochlorination evidenced by both changes in the MV peaks and formation of polyenic sequences $[10,13]$. The picture shown in the inset is another proof of the effective sensitization process. Polyenes are formed via the 'zip' mechanism and a single initiation point yields as many $\mathrm{HCl}$ molecules as the number of double bonds in the terminated polyene sequence. The basic form of MV has an absorption peak around $580 \mathrm{~nm}$ which disappears as $\mathrm{pH}$ is decreased and the dye is converted to its acidic form [10,25]. We had also studied the HQ concentration $(0.1-20 \%$ by weight) dependence of the process, as also judged by the changes in the absorbance of MV peak at $580 \mathrm{~nm}$, and found it to be linear with a threshold of ca. $0.4 \%$. However, when more than $10 \% \mathrm{HQ}$ is introduced inhomogeneous distribution within the PVC matrix results. Therefore we had chosen the 10\% HQ throughout this work for a faithful and clearer presentation of our results.

\subsection{Electrical modification}

As mentioned in Section 1, polyaniline in its basic form, PANI(EB), is soluble in common solvents, such as THF, together with PVC and can easily be cast into blend films. Following our procedure of doping the blend films via photo-dehydrochlorination we are able to create reasonable $\left(10^{-4}-10^{-2} \mathrm{~S} / \mathrm{cm}\right)$ electrical conductivity [21-23] and we expect that HQ to sensitize this process as well. UV-VisNIR spectra of PVC/PANI/HQ before and after $312 \mathrm{~nm}$ irradiation are shown in Fig. 2. The increase in the NIR tail $(800-1200 \mathrm{~nm})$ of PANI is usually attributed to the formation of the acidic form of PANI and the electrical conductivity [26-28]. The in situ created $\mathrm{HCl}$ dopes the emeraldine base (blue) and converts it to the acidic,

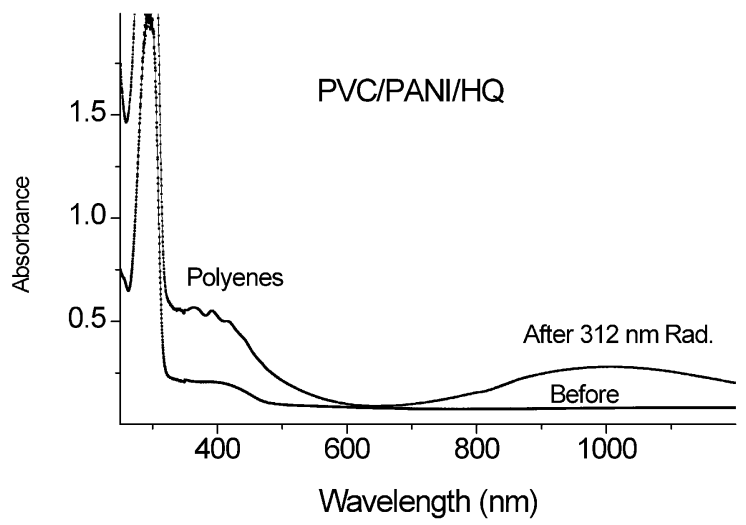

Fig. 2. UV-Vis-NIR spectra of the PVC film containing (10:5) PANI(EB) and $10 \% \mathrm{HQ}$ by weight before and after $2 \mathrm{~h}$ exposure to the $312 \mathrm{~nm}$ radiation. emaraldine salt form (green). In addition, the spectroscopic features and the electrical conductivity can be completely reversed by further exposure of the film to $\mathrm{NH}_{3}$ vapors [21-23]. However, we were not able to observe any improvement in the measured electrical conductivity of the films (still ca. $10^{-4}-10^{-2} \mathrm{~S} / \mathrm{cm}$ ) due, most probably, to insufficient concentration of PANI.

\subsection{Onset of dehydrochlorination and thermodynamic considerations}

Throughout this work our goal has been twofold. First, we had wanted to sensitize the dehydrochlorination of the PVC by HQ. Second, we had wanted to create polyenic moieties within the PVC matrix with the hope that, together with the conducting PANI moieties within the blend, they would help to increase the electrical conductivity. Our first goal is definitely achieved and is further verified by another set of measurements carried out with a set of irradiation steps at different wavelengths, starting from the red end of the electromagnetic spectrum. Fig. 3 displays the set of spectra recorded after irradiation at the specified wavelength for $10 \mathrm{~min}$ using the Zeiss UMSP 80 microscope spectrometer. As expected the most dramatic change in the spectrum takes place only in the vicinity of $310 \mathrm{~nm}$ corresponding to the strong HQ absorption (note that this onset, in our earlier publication, was mistakenly attributed to PVC-only absorption) [21]. Our second goal is also partly achieved when one examines the absorption spectrum of the dehydrochlorinated PVC to the measured spectra of the various conjugated hydrocarbon oligomers $[29,30]$ as shown in Fig. 4. As the number of conjugated double bonds in linear polyenes increases, the number of peaks in electronic spectra increases and shifts to longer wavelengths. Peaks of different polyenic sequences overlap with each other. Therefore, the electronic spectrum of dehydrochlorinated PVC is a superposition of various polyenic peaks. As can be inferred from the figure polyenes

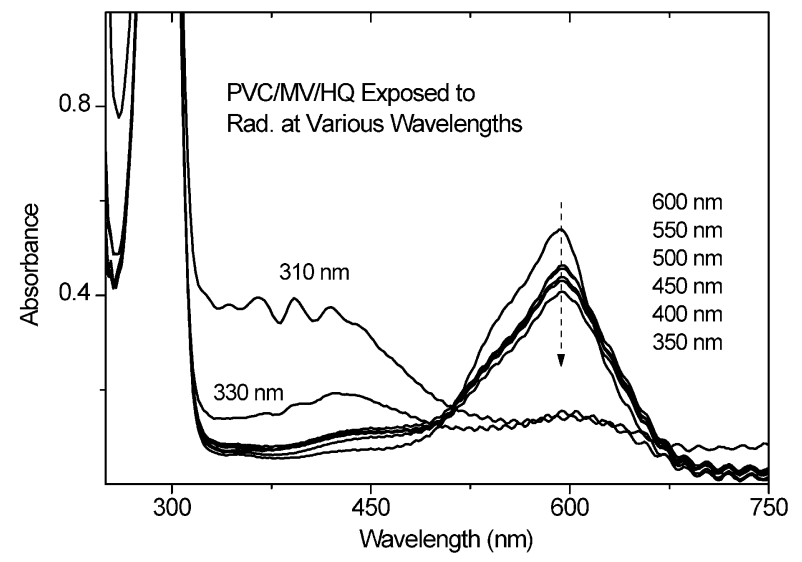

Fig. 3. UV-Vis spectra of PVC containing (10:1) methyl violet and $10 \%$ $\mathrm{HQ}$, after exposure to $15 \mathrm{~min}$ irradiation at the corresponding wavelengths, using a $75 \mathrm{~W}$ Xe lamp and starting from the red end $(600 \mathrm{~nm})$ and going towards UV. 

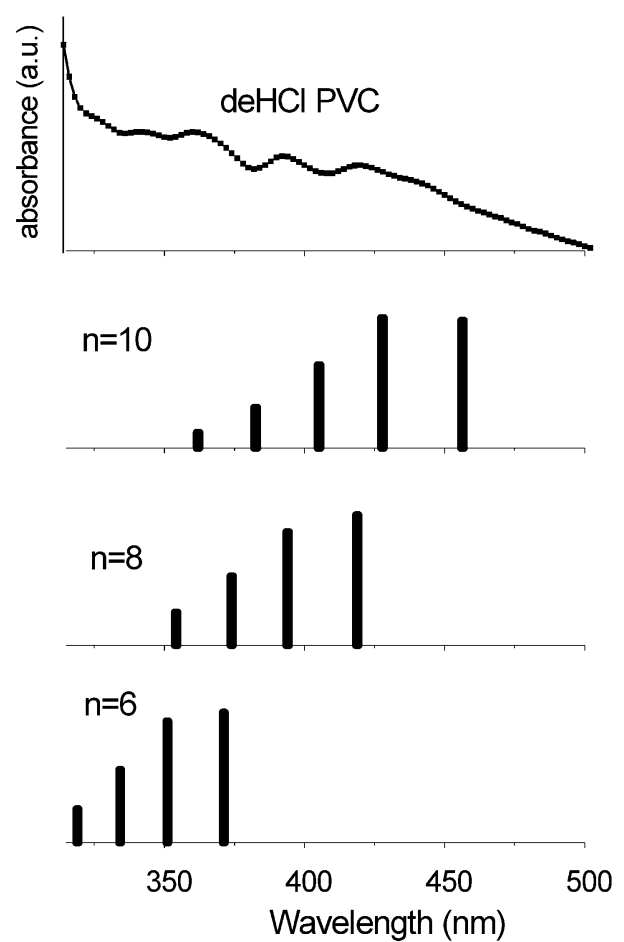

Fig. 4. Part of the UV-Vis spectrum of dehydrochlorinated PVC and the stick diagram of the absorption spectra of linear conjugated polyenes having 6,8 , and 10 double bonds, respectively. Position and relative intesities (extinction coefficients) are taken from Ref. [30]. containing up to 10 or more adjacent double bonds are formed as a result of dehydrochlorination.

The irradiation onset around $310-330 \mathrm{~nm}$ in HQ containing PVC corresponds to about $4 \mathrm{eV}$. This value is too high for a possible molecular $\mathrm{HCl}$ elimination, which can be estimated from the following gas phase reaction [25].

$\mathrm{CH}_{3} \mathrm{CH}_{2} \mathrm{Cl} \rightarrow \mathrm{CH}_{2}=\mathrm{CH}_{2}+\mathrm{HCl} \quad \Delta \mathrm{H}=72 \mathrm{~kJ} / \mathrm{mol}$.

The energy required for a $\mathrm{Cl}$ atom abstraction with a subsequent attack on the neighboring $\mathrm{H}$, leading to $\mathrm{HCl}$ elimination is about $330 \mathrm{~kJ} / \mathrm{mol}$ or $3.4 \mathrm{eV}$ (equivalent to $\mathrm{C}-$ $\mathrm{Cl}$ bond energy) which brings the onset around $360 \mathrm{~nm}$. Keeping in mind that irradiation of PVC alone at $254 \mathrm{~nm}$ is capable of dehydrochlorination but not extensive polyene formation as opposed to irradiation at $310 \mathrm{~nm}$ which both dehydrochlorinates PVC and leads to extensive polyene formation, the softer (less energetic) photons may lead to even longer chain polyenes. Hence, other sensitizers absorbing at longer wavelengths might lead to even more efficient photodegradation.

\subsection{Mechanism}

In order to shed light on the mechanism of this photosensitization we had examined a number of compounds which absorbs around $312 \mathrm{~nm}$ and are chemically similar to HQ. Of the many examined three are particularly a-)<smiles>Oc1ccc(O)cc1</smiles>

I

b-)<smiles>Oc1ccc(O)cc1</smiles>
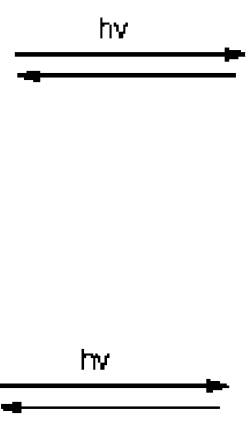<smiles></smiles>

II<smiles>O=C1C=CC(=O)C=C1</smiles>

III<smiles>COc1ccc(O)cc1CO</smiles>

IY<smiles>Oc1ccc(O)cc1</smiles>

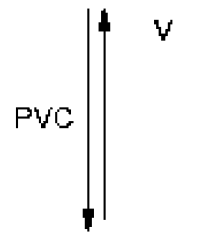

c-)<smiles>[O-]c1ccc(O)cc1</smiles><smiles>Oc1ccc(O)cc1</smiles>

Scheme 1. Possible processes of HQ in the PVC matrix after $312 \mathrm{~nm}$ UV light absorption. 
Table 1

Percentage change in the absorbance of the MV peak at $580 \mathrm{~nm}$ after exposure of PVC films containing different sensitizer/quencher and MV to 312 radiation for $30 \mathrm{~min}$

\begin{tabular}{|c|c|c|}
\hline Compound & Formula & $\begin{array}{l}\% \text { Abs. } \\
\text { change at } \\
580 \mathrm{~nm} \text { peak } \\
\text { of } \mathrm{MV}\end{array}$ \\
\hline
\end{tabular}

\section{Sensitizers}

Hydroquinone<smiles>Oc1ccc(O)cc1</smiles>

Benzophenone<smiles>O=C(c1ccccc1)c1ccccc1</smiles>

Pyrene<smiles>c1cc2ccc3cccc4ccc(c1)c2c34</smiles>

2-Acetonaphtanone<smiles>CC(=O)c1ccc2ccccc2c1</smiles>

4-Hydroxybenzoicacid

1-Napthol<smiles>C=CCOc1ccc(C(=O)O)cc1</smiles>

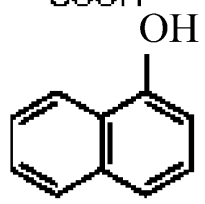

Quenchers

Ascorbic acid

33

(+HQ)

1-Nitronapthalene

(+HQ)

For all the films a constant concentration of PVC, MV and additive (10:1:1) is used.

worth mentioning namely; 1-napthol, 4-hydrobenzoic acid and benzophenone. 1-Napthol does not yield any measurable photodegradation but 4-hydroxybenzoic acid and benzophenone do. A practical measure of the relative ability of these compounds to cause photodegradation can be estimated by the percentage change in the absorbance of MV and are given in Table 1. Accordingly having absorbance at $312 \mathrm{~nm}$ is not the only prerequisite for photo-dehydrochlorination of PVC. In addition, the sensitizers should be able to transfer this absorbed energy to the PVC matrix efficiently. Benzophenone, 2-acetonaptanone, pyrene and HQ all have absorbance at $312 \mathrm{~nm}$ and they can help PVC photodegrade at $312 \mathrm{~nm}$ to varying degrees. The mechanism of the benzophenone-assisted photodegradation of PVC is studied and is reported to involve formation of triplet state of benzophenone during irradiation of the benzophenone/PVC matrix [31]. Absorption of a photon at $312 \mathrm{~nm}$ populates the $n \rightarrow \pi^{*}$ singlet state $\left({ }^{1} \mathrm{~B}\right)$ which undergoes intersystem crossing to form triplet benzophenone $\left({ }^{3} \mathrm{~B}\right)$. The reaction proceeds via hydrogen abstraction by benzophenone from the polymer matrix [32]. A similar mechanism of triplet state formation in 2-acetonaptanone, pyrene and HQ is assumed to be involved in our experiments.

Using a reverse strategy we have also examined the role(s) of quenchers; 1-nitronapthalene, which is known to be an efficient triplet state quencher and ascorbic acid, which is a well-known antioxidant, are introduced into the PVC matrix containing MV and HQ all in 1:10 ratio with respect to the PVC [33-35]. As also given in Table 1, in the presence of ascorbic acid the photodegradation takes place almost to the full extent as in the case of HQ only. However, in the presence 1-nitronapthalene no measurable photodegradation can be observed. Hence, although ascorbic acid cannot stop the photodegradation of PVC at $312 \mathrm{~nm}$ sensitized by HQ, 1-nitronapthalene is an efficient quencher of this process.

Scheme 1 summarizes the three possible processes of HQ in the PVC matrix after absorption of $312 \mathrm{~nm}$ UV light. Scheme 1(a) shows the homolytic cleavage of $\mathrm{OH}$ bond and Scheme 1(c) shows the heterolytic cleavage, whereas Scheme 1(b) indicates the excitation of HQ from the ground state to the excited singlet state and then to the triplet state. In the light of sensitization findings it is possible to eliminate heterolytic cleavage since 4-hydroxybenzoic acid is more acidic then HQ but does not lead to measurable photo-dehydrochlorination at $312 \mathrm{~nm}$ irradiation. Considering the fact that ascorbic acid, an anti-oxidant, was not very effective in terms of quenching the process we can also eliminate the route I (a) as a major pathway. Using a similar argument, since 1-nitronapthalene, a triplet quencher, was very effective, we can now state that photodegradation predominantly follows the route of I (b). Similar results were recently reported for polymer-initiated photogeneration of silver nanoparticles in poly(vinly alchohol) matrix [36]. For very long exposure times, I (a) may also be operative since $12 \mathrm{~h}$ irradiation of the films of PVC/HQ shows a strong decrease in the $\mathrm{O}-\mathrm{H}$ stretching of the HQ in the IR spectrum. However, during irradiation of the $\mathrm{PVC} /$ HQ at $312 \mathrm{~nm}$ UV light for 60 or $120 \mathrm{~min}$ there is no significant change in the absorbance of HQ in the UV-Vis spectrum.

Further experiments are needed to find other model compounds like HQ, and benzophenone in order to increase the wavelength of the irradiation. By increasing the wavelength of the irradiation one can hopefully decrease 
the damage of the irradiation on the PVC backbone leading to softer degradation and longer polyenic segments.

\section{Conclusions}

We have studied the mechanism of an efficient photosensitization process by which PVC is degraded by HQ at $312 \mathrm{~nm}$. This process yields $\mathrm{HCl}$ and polyenic moieties which can be utilized for; (i) inducing a softer degradation at longer wavelength, (ii) in situ doping (by $\mathrm{HCl}$ ) of emaraldine base PANI introduced into the PVC matrix or other purposes, (iii) helping increase the electrical conductivity of the PANI by the created polyenes in the matrix. By using other sensitizers and quenchers we postulate that the process mainly involves formation of an excited triplet of HQ which subsequently triggers a zipping reaction in PVC.

\section{Acknowledgements}

We would like to thank Prof. H. Baumgartel of the Free University of Berlin, Germany, for the use of The Zeiss microscope spectrometer and the Alexander von Humboldt Foundation of Germany for providing the funds to visit Berlin.

\section{References}

[1] Nass LI, editor. Encyclopedia of PVC. New York: Marcel Dekker; 1976.

[2] Andrady AL, Torikai A, Fueki K. J Appl Polym Sci 1989;37:935.

[3] Andrady AL, Searke ND. J Appl Polym Sci 1989;37:2789.

[4] Andrady AL, Fueki K, Torikai A. J Appl Polym Sci 1990;39:763.

[5] Misker KS, Lisitsky VV, Kolesov SV, Zaikov GE. J Macromol Sci, Rev Macromol Chem 1981;C20:243.

[6] Ivan B, Kelen T, Tudos F. Macromol Chem Macromol Symp 1989;29: 59.
[7] Mackenzie MW, Willis HA, Owen RC, Michel A. Eur Polym J 1983; 19:511.

[8] Decker C. In: Benham JL, Kinstle JF, editors. Chemical reactions on polymers. Washington, DC: American Chemical Society; 1988.

[9] Andrady AI, Searle ND. J Appl Polym Sci 1989;37:2789.

[10] Xu P, Zhou D, Zhao D. Eur Polym J 1989;25:575.

[11] Ueno K. Radiat Phys Chem 1988;31:467.

[12] Sidney LN, Lynch DC, Willet PS. Radiat Phys Chem 1990;31:779.

[13] Birer O, Suzer S. Polymer 2001;42:1833.

[14] Skotheim T, editor. Handbook of conducting polymers, vols. I and II. New York: Marcel Dekker; 1986. p. 1998.

[15] Ogun K. J Appl Polym Sci A 1994;32:33. Ogun K. J Appl Polym Sci A $1995 ; 33: 1375$.

[16] Wan W. Thin Solid Films 1995;259:188.

[17] Ouyand M, Chan CM. Polym Eng Sci 1996;36:2676.

[18] Laska J. Synth Met 1997;84:117.

[19] Malmonge JA, Dhanabalan A, Riul Jr A, Faria RM, Oliveira Jr ON. Synth Met 1999;101:801.

[20] Sertova N, Geoffrey B, Nunzi JM, Petkov I. J Photochem Photobiol, A 1998;113:99.

[21] Sevil UA, Guven O, Suzer S. J Phys Chem, B 1998;102:3902.

[22] Birer O, Suzer S, Sevil UA, Guven O. J Mol Struct 1999;482-483: 515.

[23] Sevil UA, Guven O, Birer O, Suzer S. Synth Met 2000;110:175.

[24] MacDiarmid AG, Chiang JC, Richter AF, Somarisi NLD, Epstein AJ. In: Alcacer L, editor. Conducting polymers. Dordrecht: Reidel; 1987.

[25] Lide DR. Handbook of chemistry and physics, 75th ed. Boca Raton, FL: CRC Press; 1995.

[26] Frukava Y, Hara T, Hyodo Y, Harada I. Synth Met 1986;16:189.

[27] Epstein AJ, MacDiarmid AG. In: Kuzmany H, Mehring M, Roth S, editors. Electronic properties of conjugated polymers. Berlin: Springer; 1989.

[28] Bredas JL, Street GB. Acc Chem Res 1985;18:309.

[29] Kohler BE. In: Bredas JL, Silbey R, editors. Electronic properties of conjugated polymers. Dordecht: Kluwer; 1991.

[30] Geerts Y, Klarmer G, Mullen K. In: Mullen K, Wegner G, editors. Hydrocarbon oligomers. London: Wiley; 1998.

[31] Owen ED, Balley RJ. J Polym Sci 1972;10:113.

[32] Horie K, Ando H, Mita IS. Macromolecules 1985;20:54.

[33] Patra D, Mishra AK. Sens Actuators, B 2001;80:278.

[34] Angelescu D, Vasilescu M. J Colloid Interface Sci 2001;244:139.

[35] Marcinak B, Hug GL. Coord Chem Rev 1997;159:55.

[36] Korchev AS, Bozack MJ, Staten BL, Mills G. J Am Chem Soc 2004; 126:10. 